\title{
Effects of fixed ratio training on subsequent preference for the reinforcer'
}

\author{
Charles L. Sheridan, UNIVERSITY OF ALBERTA, CALGARY Daniel M. Levinson, UNIVERSITY OF MISSOURI \\ AND VA HOSPITAL, KANSAS CITY Robert M. Cristal, YESHIVA UNIVERSITY
}

\begin{abstract}
Abstraet
Four groups of albino rats received the same number of $0.1 \mathrm{cc}$ maltose-solution reinforcements in a Skinner box, either on FR 10, FR 5, Crf, or noncontingent upon the bar press. In addition, a water-reinforced control group received the same number of $0.1 \mathrm{cc}$ noncontingent distilled water reinforcements. Subsequently, all Ss were given a cafeteria-style preference test with the same maltose solution used during training and an unfamiliar sucrose solution as alternatives. All measures revealed a decline on the part of the fixed ratio groups in preference for the solution used as a reinforcer during training. This contrasts with a previous report that the effect of high effort training on reinforcement value is incremental.
\end{abstract}

\section{Problem}

Lawrence \& Festinger (1961) have provided an integral account of the effects on resistance to extinction of training under partial reinforcement, high effort, and delay of reward. All of these training conditions force Ss to continue responding under condtions of "insufficient reward," thus giving rise to a dissonant relationship between the organism's behavior and the insufficiency of the reward which is contingent on that behavior. The dissonance is resolved by developing "extra attractions" related to various aspects of the training situation. It is the development of these extra attractions which, because they persist during extinction, results in heightened resistance to extinction.

In consonance with the Lawrence and Festinger hypothesis, Lewis (1964) has shown that high-effort training conditions result in an enhancement of reward value. Lewis trained rats to pull against a weighted harness in order to reach a food reward, then, under unrestrained conditions, measured their speed of approach to the same reward, as well as the rate of eating and amount eaten when Ss were nearly satiated. There was a statistically reliable tendency for higheffort Ss to run and eat faster, and to eat more when nearly satiated than low-effort Ss.

The experiment reported here attempts to evaluate the generality of nondecremental effects of effort by measuring the effects of partial reinforcement training on preference for the reward used during training.

\footnotetext{
Subjerts

Ss were 40 male Sprague-Dawley albino rats from 65 to 90 days old at the beginning of the experiment.

Apparatus

The training apparatus consisted of two identical, standard Skinner boxes, 7 in $\times 7$ in $\times 91 / 2$ in (inside dimensions) with telegraph-key bars, counters, and hypodermic syringe liquid reinforcement systems
}

permitting accurate delivery of a $0.1 \mathrm{cc}$ reinforcement. The reinforcement solution was a 0.1 molar maltose solution made by dissolving appropriate amounts of "Maltose, practical" (made by Matheson, Coleman, and Bell, Norwood, Ohio and East Rutherford, N.J.) in distilled water.

Preference testing took place in a $161 / 4$ in $\times 91 / 2$ in $\times 7$ in (inside dimensions) rat living cage with two ordinary $500 \mathrm{cc}$ water bottles placed side by side with drinking tubes projecting into the cage approximately 1 in apart. The solution as a test alternate to the above mentioned $0.1 \mathrm{M}$ maltose was $0.1 \mathrm{M}$ sucrose made by dissolving ordinary cane sugar in distilled water. All solutions were prepared freshly each day.

\section{Procedure}

Deprivation and Shaping. All Ss were placed on 23-hr. water deprivation 4 days prior to training, then were watered for $1 \mathrm{hr}$. per day, just after running, until the conclusion of the study. Food was available to them at all times. Shaping took place over a 3 day period, 20 reinforcements being given on each of the days. The shaping procedure differed for the various groups, each of which contained 8 Ss. Water Controls (WC) were simply given 20 consecutive $0.1 \mathrm{cc}$ distilled water reinforcements which were delivered without regard to any response made by $\mathrm{S}$, the only requirement being that he consume the solution. Maltose Controls (MC) received shaping identical to that of Group WC except that the $0.1 \mathrm{M}$ maltose solution was used as the reinforcer. The remaining 3 groups (Crf, FR 5, and FR 10) were shaped to bar press during this phase of training, all Ss being reinforced with the maltose solution for each bar press to the end of the 3 day shaping period.

Training. Training lasted for 6 days, and, once again, 20-0.1 cc reinforcements per day were given to each $\mathrm{S}$, regardless of the group to which he belonged. Groups WC and MC were treated during training just as they had been during shaping -20 noncontingent reinforcements were given each day, distilled water for Group WC and $0.1 \mathrm{M}$ maltose for Group MC. The remaining 3 groups all continued to be reinforced with $0.1 \mathrm{M}$ maltose, Group Crf being reinforced for each bar press, Group FR 5 for every 5th, and Group FR 10 for every 10 th bar press.

Testing. All groups were tested in an identical fashion. $\mathrm{S}$ was placed in the testing cage and confronted with two drinking tubes, one providing the $0.1 \mathrm{M}$ maltose used during training and the other providing $0.1 \mathrm{M}$ sucrose which Ss had not previously encountered. Each $\mathrm{S}$ was given $20 \mathrm{~min}$. daily in the preference testing apparatus for the 4 consecutive days immediately following training. The right-left position of the solutions was alternated from day to day. The number of cc's of each solution consumed was recorded for the 4 test sessions.

\section{Results}

The median cc's of each solution and of both solutions combined which were consumed over the four 20-min. sessions by the various groups is presented in Table 1.

In general, the amount of maltose solution consumed declined as a function of increasing response demand during training and the amount of sucrose solution increased. Whether we consider consumption of maltose or of sucrose solution, the two groups trained under low-effort contingencies (MC and Crf) did not differ reliably from each other, nor did the two groups trained under high-effort contingencies (FR 5 and FR 10). 
Table 1. Median cc's of maltose, sucrose, and combined maltose and sucrose solutions consumed over the four test sessions.

\begin{tabular}{|c|c|c|c|c|c|}
\hline Solution & $\underset{M C}{\text { Group }}$ & $\begin{array}{c}\text { Group } \\
\text { Crf }\end{array}$ & $\begin{array}{l}\text { Group } \\
\text { FR5 }\end{array}$ & $\begin{array}{l}\text { Group } \\
\text { FR } 10\end{array}$ & $\begin{array}{c}\text { Group } \\
\text { WC }\end{array}$ \\
\hline Maltose & 111.0 & 97.5 & 90.5 & 74.5 & 70.5 \\
\hline Sucrose & 24.0 & 24.0 & 38.0 & 28.5 & 41.5 \\
\hline $\begin{array}{l}\text { Maltose }+ \\
\text { Sucrose }\end{array}$ & 135.5 & 120.0 & 133.0 & 113.5 & 114.0 \\
\hline
\end{tabular}

However, when pooled scores for MC and Crf were compared with similarly pooled scores for FR 5 and FR 10, it was seen that the amount of maltose consumed was reliably less following fixed ratio training $(p<.002$, Mann-Whitney U) and the amount of sucrose consumed was reliably greater following ratio training $(p<.02$, Mann-Whitney U)。

The combined amount of maltose and sucrose solution consumed dropped off considerably in the FR 10 group, and differed reliably from the total amount consumed by Group MC ( $p=.02$, Mann-Whitney U). Consequently, the amount of maltose solution consumed by each $\mathrm{S}$ was converted to a percentage of the total amount of both solutions drunk. The median percentages of maltose solution consumed by groups MC, Crf, FR 5, FR 10, and WC were, respectively, 80.2, 82.9, 69.3, 72.2, and 69.7. It is also possible to convert the scores into relative values by computing a maltose/sucrose ratio for each animal, in which case the respective medians were $4.24-1,4.92-1,2.26-1,2.64-1$ and 1.63-1.

Using the maltose percentage measure, once again the MC and Crf groups did not approach a reliable difference from each other, nor did the FR 5 and FR 10 groups, but when these groups were combined, the ratio groups were seen to consume a reliably smaller percentage of maltose $(p<.02$, Mann-Whitney $U)$ than the combined MC and Crf groups. Furthermore, the pooled fixed ratio groups differed from the Crf group taken by itself with a $\mathrm{p}<.05$.

Group WC differed reliably from Group MC in percentage of maltose consumed $(U=4 ; p=.002)$, reflecting the effects of adaptation to the maltose solution. The decremental effects of FR training are superimposed on the incremental effects of familiarization with the solution. Ratio training counteracts these familiarization effects to such an extent that performance of the FR 10 group is nearly identical to that of Group WC with respect both to total amount of combined maltose + sucrose solution consumed and to percentage of maltose consumed.

\section{Discussion}

Instead of the expected increase in preference for the reward following partial reinforcement training with that reward as reinforcer, a statistically reliable decrease was observed. Any facilitative "extra attractions" developed under the conditions of the present experiment must be related to aspects of the situation other than the goal object.

The determinants of this decrement in preference are in need of further analysis, since the training conditions of the fixed ratio groups did not differ from those of the other groups in response effortfulness alone. For example, differences in the temporal patterning of reinforcements coincide with the variations in work requirements. Although it is clear that the net effect of ratio training on "reward value" is decremental, the exact basis of this decremental effect remains to be determined.

Until the source of the decremental effect is known, it is difficult to adequately relate the present findings to the nondecremental effects of effort reported by Lewis (1964). However, it is not unlikely that the effects observed by Lewis were due to the generalization from the training to the test situation of a tendency to concentrate effort on the goal object. Lewis himself pointed out that weighting the harness seems to reduce activity not directed toward obtaining the goal, but did not seem to realize that this observation casts doubt on the adequacy of his measure of reward value. The present interpretation would suggest that high-effort Ss would consume more of anything than low-effort Ss, given the conditions of his experiment. A preference test presumably constitutes a far more valid measure of "reward value."

\section{References}

LAWRENCE, D。H., \& FESTINGER, L. Deterrents and reinforcement, Stanford, Calif.: Stanford University Press, 1962.

LEWIS, M. Some nondecremental effects of effort. J. comp. physiol. Psychol., 1964, 57, 367-372.

Note

1. This study was conducted at the University of Missouri, Kansas City, and was supported in part by Fund 8200, U.S.V.A. Hospital Neuropsychology Laboratories, Kansas City. 